\title{
An Empirical Study of Chinese Learners' Intercultural Sensitivity
}

\author{
Xinmin Hou \\ Study Abroad Program, Xi'an International Studies University, Xian, China \\ Email: philiphou78@yahoo.com
}

\begin{abstract}
This paper is a pilot study which endeavors to evaluate the status quo of the Chinese learners intercultural sensitivity. The study provides first-hand information for intercultural education in China.
\end{abstract}

Index Terms - intercultural sensitivity, intercultural communication competence

\section{INTRODUCTION}

The present study aims at assessing the intercultural sensitivity of EFL learners in China, especially in Xi'an International Studies University. A questionnaire is used to obtain related data.

The subjects involved in the study are middle-aged Chinese learners. They come from different parts of China and major in science and arts. Most of them are university lecturers and they are selected by China Scholarship Council to be visiting scholars. They are scheduled to go abroad to continue their research work for one year. Before they start their journey, they need to study for half a year in one of the eleven training departments under directly leadership of the Educational Ministry of China. At the end of their training program, they have to take an English proficient test. If they are lucky enough to pass it, they can be sent abroad. Before they embark their trip abroad, it is quite necessary to have a clear picture of their intercultural communication competence so that we may gather some valuable information for the training of the upcoming Chinese learners.

Altogether 120 learners in four classes are selected. Among them 115 feedbacks are received. After deleting the questionnaires with more than one missing data, there are 95 subjects left in the study, consisting of 50 males and 45 females, of which 80 are aged between 30 - 40, and 15 between 41-50.

A questionnaire is employed for the study. The questionnaire consists of two parts. Part one gives the general introduction to the author and the instruments. Part two is Chen and Starosta's ISS (Intercultural Sensitivity Scale).

The ISS is a 24-item, 5-likert scale, which are Interaction Engagement, Respect for Cultural Differences, Interaction Confidence, Interaction Enjoyment and Interaction Attentiveness. For each item in the scale, there are five choices: $5=$ strongly agree, $4=$ agree, $3=$ uncertain, $2=$ disagree, and $1=$ strongly disagree.

The first factor--Interaction Engagement includes 7 items, which are related to participants' feeling of participation in intercultural communication. The second factor--Respect for Culture Difference includes 6 items, which are about how participants orient to or tolerate their counterparts' culture and opinion. The third factor--Interaction Confidence has 5 items, which are concerned with how confident participants are in the intercultural setting. The forth factor---Interaction Enjoyment includes 3 items, which deal with participants' positive or negative reaction towards communicating with people from different cultures. The last one--Interaction Attentiveness has 3 items, which are concerned with participants' effort to understand what is going on in intercultural interaction.

\section{FINDINGS AND DISCUSSIONS}

Factor 1 Interaction Engagement

\begin{tabular}{|c|c|c|c|c|c|c|c|c|c|c|}
\hline \multirow{2}{*}{\begin{tabular}{|c|} 
Choices \\
Item \\
\end{tabular}} & \multicolumn{10}{|c|}{ The number of choices and their percentage for each item in the factor } \\
\hline & 5 & Percentage & 4 & Percentage & 3 & Percentage & 2 & Percentage & 1 & Percentage \\
\hline \begin{tabular}{|c|}
1 \\
\end{tabular} & 30 & $32 \%$ & 55 & $58 \%$ & 7 & $7 \%$ & 2 & $2 \%$ & 1 & $1 \%$ \\
\hline 11 & 23 & $24 \%$ & 32 & $34 \%$ & 28 & $30 \%$ & 7 & $7 \%$ & 5 & $5 \%$ \\
\hline 21 & 23 & $24 \%$ & 50 & $53 \%$ & 15 & $16 \%$ & 6 & $6 \%$ & 1 & $1 \%$ \\
\hline 22 & 5 & $5 \%$ & 16 & $17 \%$ & 36 & $38 \%$ & 28 & $30 \%$ & 10 & $10 \%$ \\
\hline
\end{tabular}

The first factor Interaction Engagement is concerned with participant's feeling of participation in intercultural communication. As can be seen from table 1, about $58 \%(24 \%+34 \%)$ of the subjects agree that they tend to wait before forming an impression of culturally-distinct counterparts (item 11). This indicates that they will not jump to a conclusion before patiently listening to the counterparts. In other words, they will not easily be influenced by stereotypes which are the perceptions or beliefs we hold about groups or individuals based on previously formed 
opinions and attitudes (He, Jamison, Antoniou and Whiteman, 2004). Stereotype helps to simplify the complex task of identification and makes it easier to decide what behavior is appropriate and what behavior is to expect in a new situation. However, stereotypes mainly apply to the behavior norm of groups rather than individual. According to Adler, they are harmful when adhered to rigidly, and become counterproductive when placing people in the wrong group, especially if they are oversimplified or over-generalized (He, Jamison, Antoniou and Whiteman, 2004). With the development of the society and education nowadays, on one hand, Chinese learners usually have many chances to meet and communicate with people from different cultures, for example, some foreign teachers and scholars come to China to give academic lectures; on the other hand, they learn some of the cultural knowledge from books or other media. The cultural knowledge, to some extent, can be considered as the generalizations or stereotypes. In the process of communicating with the culturally different people, Chinese learners may find that there are some discrepancies between the cultural knowledge they learn from books and the real intercultural communication situation in which they interact with foreigners. Therefore, they tend to wait and meditate whether these stereotypes are right or not. It makes sense why more than half of them show such an attitude. Such an attitude will help them with the development of their general intercultural communication competence and can usefully influence them in their future interaction with people from different cultural backgrounds.

As many as $90 \%(32 \%+58 \%)$ of the subjects express that they "enjoy interacting with people from different cultures" (item 1). $81 \%(32 \%+49 \%)$ of the subjects are open-minded to people from different cultures (item 13) while $66 \%(15 \%+51 \%)$ have a feeling of enjoyment towards differences between their culturally-distinct counterpart and them (item 24). These students can be divided into the category that Chen and Starosta (1997) regard as with high self-esteem and open-minded. Thus they usually hold positive attitude in intercultural communication and are willing to openly explain and accept differences between them and their cultural counterparts.

Moreover, $62 \%(17 \%+45 \%)$ of the subjects often show their culturally-distinct counterpart their understanding through verbal or non-verbal cues (item 23$) ; 77 \%(24 \%+53 \%)$ of the subjects often give positive responses to their culturally different counterpart during their interaction (item 21). These figures indicate that a large majority of Chinese learners enjoy interacting with culturally different counterparts. However, only $22 \%(5 \%+17 \%)$ of the subjects avoid the situation when he or she has to deal with culturally-distinct persons (item 22). These students do not master the skills needed in intercultural communication events. Therefore, not only the desire and feeling of enjoyment towards differences between cultures but also proper communicating skills are needed to promote and smoothen intercultural communication.

Factor 2 Respect for Cultural Difference

\begin{tabular}{|c|c|c|c|c|c|c|c|c|c|c|}
\hline \multirow{2}{*}{ Choices } & \multicolumn{10}{|c|}{ The number of choices and their percentage for each item in the factor } \\
\hline & 5 & Percentage & 4 & Percentage & 3 & Percentage & 2 & Percentage & 1 & Percentage \\
\hline 2 & 3 & $3 \%$ & 3 & $3 \%$ & 11 & $12 \%$ & 47 & $49 \%$ & 31 & $33 \%$ \\
\hline 7 & 3 & $3 \%$ & 8 & $8 \%$ & 6 & $6 \%$ & 52 & $55 \%$ & 26 & $27 \%$ \\
\hline 8 & 53 & $56 \%$ & 31 & $33 \%$ & 6 & $6 \%$ & 3 & $3 \%$ & 2 & $2 \%$ \\
\hline 16 & 34 & $36 \%$ & 46 & $48 \%$ & 7 & $8 \%$ & 5 & $5 \%$ & 3 & $3 \%$ \\
\hline 18 & 3 & $3 \%$ & 5 & $5 \%$ & 21 & $22 \%$ & 38 & $40 \%$ & 28 & $30 \%$ \\
\hline 20 & 5 & $5 \%$ & 17 & $18 \%$ & 31 & $33 \%$ & 28 & $30 \%$ & 14 & $14 \%$ \\
\hline
\end{tabular}

The second factor--Respect for Cultural Difference is mainly about how participants orient to or tolerate their counterparts' culture and opinions. $6 \%(3 \%+3 \%)$ of the subjects agree that "people from other cultures are narrow-minded" (item 2); $11 \%(3 \%+8 \%)$ of the subjects "don't like to be with people from different cultures" (item 7); $89 \%(56 \%+33 \%)$ of the subjects "respect the values of people from different cultures" (item 8$) ; 84 \%(36 \%+48 \%)$ of the subjects "respect the ways people from different cultures behave" (item 16); only $8 \%(3 \%+5 \%)$ "would not accept the opinions of people from different cultures" (item 18); All these indicate that the majority of the subjects do not reject opinions held by their culturally-different counterparts; neither do they hesitate to associate with people of different cultures. On the other hand, they are open-minded, willing to accept and appreciate different opinions and ideas. Acceptance of cultural difference represents a major shift from ethnocentrism to ethnorelativism. Cultural difference is no longer judged by the standards of one's own culture and "those who have moved into this stage have undergone a shift in their perception of difference; they no longer find difference threatening."

However, still $23 \%(5 \%+18 \%)$ of the subjects think their culture is better than other cultures (item 20). It is possible that some Chinese learners who have awareness of the cultural differences and similarities may be unwilling to respect those cultural differences because of some deep-rooted perceptions, stereotypes or prejudices. Bennett (1993) notes that group or individual whose intercultural sensitivity is in the ethnocentric stage will react to cultural difference with defensive actions, and they can only perceive the world from their only cultural reality. Though those Chinese learners have a lot of chances to obtain knowledge about different cultures through many channels such as journals, internet, and mass media, some of these channels may be the production of obvious ethnocentric and self-centered points of view. And this will cast impact on their perspective. 
Factor 3 Interaction Confidence

\begin{tabular}{|c|c|c|c|c|c|c|c|c|c|c|}
\hline \multirow{2}{*}{$\begin{array}{c}\text { Choices } \\
\text { Item }\end{array}$} & \multicolumn{10}{|c|}{ The number of choices and their percentage for each item in the factor } \\
\hline & 5 & Percentage & 4 & Percentage & 3 & Percentage & 2 & Percentage & 1 & Percentage \\
\hline $\mathbf{3}$ & 10 & $11 \%$ & 45 & $47 \%$ & 33 & $35 \%$ & 5 & $5 \%$ & 2 & $2 \%$ \\
\hline 4 & 3 & $3 \%$ & 33 & $35 \%$ & 22 & $23 \%$ & 26 & $27 \%$ & 11 & $12 \%$ \\
\hline 5 & 4 & $4 \%$ & 23 & $24 \%$ & 51 & $54 \%$ & 16 & $17 \%$ & 1 & $1 \%$ \\
\hline 6 & 7 & $7 \%$ & 26 & $27 \%$ & 41 & $43 \%$ & 19 & $20 \%$ & 2 & $2 \%$ \\
\hline 10 & 14 & $15 \%$ & 43 & $45 \%$ & 24 & $25 \%$ & 12 & $13 \%$ & 2 & 2 \\
\hline
\end{tabular}

The third factor--Interaction Confidence has 5 items, which are concerned with how confident participants are in the intercultural setting. The above table shows that 58\% $(11 \%+47 \%)$ of the subjects feel pretty sure of themselves in interaction with people from different cultures (item 3); $38 \%(3 \%+35 \%)$ of the subjects find it very hard to talk in front of people from different cultures (item 4); $28 \%(4 \%+24 \%)$ of the subjects know what to say when interacting with people from different cultures (item 5); $34 \%(7 \%+27 \%)$ of the subjects can be as sociable as they want to be when interacting with people from different cultures (item 6); $60 \%(15 \%+45 \%)$ of the subjects feel confident when interacting with people from different cultures (item 10). All these indicate that nearly half or more of the Chinese learners do not have much confidence when interacting with culturally-distinct people.

In his many years of study with over twenty-five thousand learners of language living and studying abroad, Coleman (2002) has pointed out that "the problem of confidence clearly needs addressing" (p.1). He has found that linguistic and personal confidence appeared frequently under anticipated worries and problems. Rodgers and McGoven (2002) have also noticed that individuals must meet the challenges of language barriers, unfamiliar customs and practices, and cultural variations in verbal and nonverbal communication styles in order to achieve successful intercultural understanding. As a result, linguistic and cultural barriers often carry evaluative and affective consequences for interactants in an intercultural context, resulting in their lacking of confidence.

According to the above findings, it can be inferred that the subjects' weakness in interaction confidence should also be derived from challenges in both language and cultural aspects. These two barriers must be overcome in order to improve interaction confidence. As second language and culture learning is rather a comprehensive and chronological process, there is a long way for Chinese learners to go in perfecting their foreign language and cultural competence. Only a linguistic competence can hardly help Chinese learners achieve a fairly satisfactory intercultural competence without rich intercultural experience in reality. Through adjusting Chinese learners' attitude and behavior in intercultural interaction and gaining more intercultural knowledge consciously, their interaction confidence will be improved and then their intercultural sensitivity will be raised.

Factor 4 Interaction Enjoyment

\begin{tabular}{|c|c|c|c|c|c|c|c|c|c|c|}
\hline \multirow{2}{*}{$\begin{array}{c}\text { Choices } \\
\text { Item }\end{array}$} & \multicolumn{10}{|c|}{ The number of choices and their percentage for each item in the factor } \\
\hline & 5 & Percentage & 4 & Percentage & 3 & Percentage & 2 & Percentage & 1 & Percentage \\
\hline 9 & 1 & $1 \%$ & 12 & $13 \%$ & 22 & $23 \%$ & 42 & $44 \%$ & 18 & $19 \%$ \\
\hline 12 & 2 & $2 \%$ & 14 & $15 \%$ & 19 & $20 \%$ & 38 & $40 \%$ & 22 & $23 \%$ \\
\hline 15 & 2 & $2 \%$ & 8 & $8 \%$ & 14 & $15 \%$ & 50 & $53 \%$ & 21 & $22 \%$ \\
\hline
\end{tabular}

The fourth factor--Interaction Enjoyment, as defined by Chen and Starosta (2000), is about participants' positive or negative reaction towards communicating with people from different cultures. Jettmer and Nass (2002) believe that enjoyment of the interaction is composed of the following items: pleasantness of the interaction, productiveness of the interaction, enjoyment of the interaction, and cooperative nature of the interaction.

As shown in the above table , only $10 \%(2 \%+8 \%)$ of the subjects "often feel useless when interacting with people from different cultures" (item 15); $14 \%(1 \%+13 \%)$ of the subjects admit that they "get upset easily when interacting with people from different cultures" (item 9); and $17 \%(2 \%+15 \%)$ of the subjects "often get discouraged when they are with people from different cultures" (item 12). However, there are $23 \%$ of the subjects who are uncertain about item 9 , $20 \%$ of the subjects who are uncertain about item 12 , and $15 \%$ of the subjects who are not sure of item 15 .

This phenomenon indicates the following points: a) more than half of the subjects have experienced a relatively high degree of enjoyment in terms of the pleasantness, productiveness and enjoyment of interaction, and are relatively optimistic when they encounter some problems in intercultural communication situation and have enough courage to deal with difficulties when interacting with culturally-distinct people; b) less than one fourth of the subjects are uncertain about the three items, which indicates that this group of subjects are not sure of their own feelings when interacting with people from different cultures or when encountering some problems.

The author concludes two reasons for the findings. Firstly the subjects' inadequate interaction confidence may partly account for this phenomenon. It is the scant confidence in intercultural communication that can easily lead to frustration when they encounter some problems. Another reason is the learning environment of our traditional English class which is of teacher-dominant, student-submissive nature and in which students are accustomed to being silent listeners (Liu liebin 2001). The chance of interaction between teacher and students as well as among students is limited, therefore they do not have much rewarding experience with regard to pleasantness of interaction, productiveness of interaction, enjoyment of interaction or cooperative nature of interaction. What they may embrace are more of fear of making mistakes, hesitancy about answering questions and a reluctance to be singled out rather than enjoying the process of 
interaction (ibid).

\begin{tabular}{|c|c|c|c|c|c|c|c|c|c|c|}
\hline & \multirow{2}{*}{\multicolumn{10}{|c|}{ The number of choices and their percentage for each item in the factor }} \\
\hline \multirow{2}{*}{$\begin{array}{c}\text { Choices } \\
\text { Item } \\
\end{array}$} & & & & & & & & & & \\
\hline & 5 & Percentage & 4 & Percentage & 3 & Percentage & 2 & Percentage & 1 & Percentage \\
\hline 14 & 19 & $20 \%$ & 43 & $45 \%$ & 27 & $28 \%$ & 3 & $3 \%$ & 3 & $3 \%$ \\
\hline 17 & 32 & $34 \%$ & 43 & $45 \%$ & 14 & $15 \%$ & 5 & $5 \%$ & 1 & $1 \%$ \\
\hline 19 & 9 & $9 \%$ & 32 & $34 \%$ & 36 & $38 \%$ & 17 & $18 \%$ & 1 & $1 \%$ \\
\hline
\end{tabular}

The last factor--Interaction Attentiveness deals with participants' effort to understand what is going on in intercultural interaction. The concept is similar to what Cegala (1981) calls "Interaction Involvement", which according to the author, consists of three concepts that are related to the ability of sensitivity: responsiveness, attentiveness, and perceptiveness. People with Interaction Attentive ability tend to be intercultural sensitive enough with conversational procedure and maintain an appropriate interaction (Chen \& Starosta, 2000).

According to the above table, $79 \%(34 \%+45 \%)$ of the subjects "try to obtain as much information as they can when interacting with people from different cultures" (item 17). It is very helpful for a productive communication. Meanwhile, $65 \%(20 \%+45 \%)$ of the subjects are "very observant when interacting with people from different cultures" (item 14). However, $43 \%(9 \%+34 \%)$ of the subjects are "sensitive to their culturally-distinct counterpart's subtle meanings during their interaction" (item 19). This indicates that more than half of the Chinese learners are not attentive and sensitive enough in interaction, so they can not capture the subtle meanings revealed by their counterparts either verbally or nonverbally.

In order to have a clear picture of the overall situation of the Chinese learners' intercultural sensitivity, it is necessary to calculate the average score of each factor and the average score of the five factors. The following table clearly shows this information.

The average score of the five factors

\begin{tabular}{|c|c|c|c|c|c|c|}
\hline Factor 1 & Factor 2 & Factor 3 & Factor 4 & Factor 5 & Sum & Average \\
\hline 3.7067 & 2.8985 & 3.2842 & 2.2701 & 3.6947 & 15.8542 & 3.1708 \\
\hline
\end{tabular}

From the above table, we can see that the highest average score of the five factors is Factor 1 (3.7067), closely followed by Factor 5 (3.6947). The lowest average score is Factor 4 (2.2701) followed by Factor 2 (2.8985), while Factor 3 (3.2842) remains in the middle. The average score of the five factors is 3.1708 .

\section{CONCLUSION}

In summary, the result shows the general situation of the Chinese learners is that they have gone beyond the uncertain stage $(3<3.1708<4)$ and is approaching the stage of agreement, which indicates that all the Chinese learners have a relatively positive attitude toward intercultural communication. Of the total five factors, students display their strongest ability in their "Interaction Engagement" (factor 1, 65\% on average, mean score 3.7067) and weakest in their "Interaction Enjoyment" (factor 4, about 14\% on average, mean score 2.2701)). The combination of the five factors can ideally reflect the intercultural sensitivity of the subjects.

According to the evaluation conducted in this study, we can see that there is still much room available for improvement in terms of the general level of Chinese learners' intercultural sensitivity. Improving their intercultural sensitivity will help their intercultural communication more successfully and effectively because those Chinese learners with their special educational background and professional skills always serve as bridges between different cultures. Developing their intercultural sensitivity will better equip them for the upcoming responsibility.

\section{REFERENCES}

[1] Adler, R. B. and Towne, N. (1996). Looking Out/ Looking In. NY: Holt, Rinehart and Winston.

[2] Bennett, M J. (1993). Toward Ethnocentrism: A Developmental Approach to Training for Intercultural Sensitivity. Paige R M. Education for the Intercultural Experience. Yarmouth, ME: Intercultural Press, pp.21-71.

[3] Cegala, D. J. (1981). Interaction involvement: A cognitive dimension of communicative competence. Communication Education, 30:109-121.

[4] Chen, G. M, \& Starosta, W.J. (1997). A review of the concept of intercultural sensitivity. Human Communication, issue 1, pp.1-16.

[5] Chen, G. M, and Starosta and W.J. (2000). "The Development and Validation of the Intercultural Sensitivity Scale." Human Communications issue 3, pp.1-15

[6] Coleman, J. (2002). Student voices on residence abroad. http://www. lang.ltsn.ac.uk/resources/ paper.aspx/resources

[7] He, Jamison, Antoniou, and Whiteman, K. (2004). Intercultural Communication Skills. Guangdong, Zhongshan University Press.

[8] Jettmer, E.\& Nass, C. (2002). Adaptive Testing: Effects on User Performance, http:// www.danger-island.com

[9] Liu L. B. (2001). A Discussion on Language Teaching through Culture. MA thesis, East China Normal University.

[10] Rodgers, J. S. \& McGoven, T. (2002). Attitudes towards the culturally different: the role of intercultural communication 
barriers, affective responses, consensual stereotypes, and perceived threat. International Journal of Intercultural Relations. 26: 609-631.

Xinmin Hou was born in Xi'an, China in 1959. He completed his postgraduate program in linguistics and literature from Sichuan University, China in 1990.

He is currently an associate professor in the Study Abroad Program, Xi'an International Studies University, Xi'an, China. His research interests include intercultural communication and language testing.

Professor Hou is a rather prolific writer with more than 20 books and 10 papers published in China. 